\title{
Testing of Pigmented Coatings on Thermal Sensitised Stainless Steel
}

\begin{abstract}
Purpose -It was the objective of the presented research to verify the capability of pigmented coatings to mitigate the effects of thermal sensitisation of 430 Stainless Steel.
\end{abstract}

Methodology/approach - Experimental weld joints of non-stabilised ferritic corrosion resistant steel type AISI 430 were prepared. Protective coatings in several variants were applied to a number of weldments, subsequently subject to corrosion tests in $\mathrm{SO}_{2}$ and $\mathrm{NaCl}$. The anticorrosive efficiency of the coatings was evaluated by means of normative visual assessment and metallographic analysis of the mechanism and depth of corrosion damage.

Findings - Anticorrosive efficiency of the tested coatings was experimentally established under conditions where differences were identified in structural changes caused by welding, or resulting from mechanical damage to the coating. Differences in the progress of corrosion damage caused by phase changes in the heat-affected zone were established.

Practical implications - Tests of anticorrosive efficiency of coatings of selected types provided information about possible reduction in sensitisation of welded non-stabilised steel. The effect of the investigated processes on degradation of anticorrosive resistance was identified.

Originality - A specific effect of phase changes accompanying welding on the corrosion mechanism was described and so were the reasons underlying development of corrosion damage at visually identical character of surface damage.

Keywords - destabilisation, welding, corrosion resistant ferritic steels, anticorrosive pigment, zinc, organic coating

Classification - research paper

\section{Introduction}

Ferritic, non-stabilised stainless steels represent a financially efficient solution, primarily in connection with thick welded structures, owing to problems related to the manufacture of stabilised variants of anticorrosive materials. The effectiveness of stabilisation by microalloying is doubtful, especially in close proximity to the fusion zone where the primary carbides, and potentially nitrides, are dissolved; a process accompanied by the possible formation of chromium-enriched carbides. Recent papers (Warmelo et al., 2007) have confirmed this. Additionally, when the heat input is limited and cooling is rapid, stabilised steels exhibit a strong tendency to precipitate carbides over the critical temperature range. The formation of precipitates of type $\operatorname{Ti}(\mathrm{C}, \mathrm{N})$ during subsequent transformation does not proceed under optimal conditions and the steel loses its passivation capacity. The extent of sensitisation depends on phase changes that take place in the steel; from the point of view of corrosion resistance, maximum re-austenitisation followed by martensite formation inside the heat-affected zone have a favourable effect. The advantage of ferritic steels, compared to austenitic ones, for a given application is connected to the often-undesirable processes of strain hardening of austenite.

Non-stabilised types of ferritic steels are prone to various forms of corrosive damage, such as intercrystalline corrosion, crevice corrosion or pitting corrosion. The corrosion resistance of ferritic corrosion resistant steels may be degraded substantially by thermal load during the welding process. Layers of crystallites containing $\mathrm{Mn}, \mathrm{Cr}$ and $\mathrm{Fe}$, covering a chromium-rich base layer of polycrystalline chromium oxide $\mathrm{Cr}_{2} \mathrm{O}_{3}$ have been identified in the corrosion product layer on these steels after they have been subjected to protracted exposition at around $800^{\circ} \mathrm{C}$ (Rufnera et al., 2008). 
The mechanism of intercrystalline corrosion, the most-often-encountered problem in various applications of this type of steel, has been described at length in a number of papers. The most frequently-accepted theory of sensitisation comprises depletion of active chromium close to the grain boundary to a concentration level that is below the minimum necessary for its stabilisation effect to be maintained by the material (Zahumensky et al., 1999). Pitting corrosion can represent the limiting factor in applications where the weld joint is subject to dynamic load. Many papers have been devoted in this connection to the adverse effect of impurities, especially impurities based on sulphur and phosphorus. However, some issues remain open, owing to existence of inconclusive results (Lo et al., 2009). The most recent papers deal with the effect of thermal load on mechanical properties (Mohyla, 2004) and with the effect of plastic flow on passivation characteristics. Deformation bands or phase boundaries were identified as preferential locations for pitting corrosion (Barbucci et al., 2002). The effect of deformation on corrosion is always complex, however, and no general relationship has been established between the scope of damage and the degree of cold deformation (Peguet, 2007). The results of studies to evaluate the effect of strain on the time until pit corrosion initiation were ambiguous (Salvage et al., 1983) vs. (Vignal et al., 2004). Structural changes and residual stress after deformation affect the corrosion behaviour. Chemical composition and the thickness of the protective film depend in austenitic steels primarily on cold deformation (Phadnis, 2003).

Stainless steel brings cost and environmental benefits in automotive applications due to high corrosion resistance and excellent manufacturability. Stainless steel is now a candidate for use in structural frameworks and body paneling of transport applications. High strength stainless steel offers excellent energy absorption in relation to strain rate under impact, i.e. weight savings and enhanced crashworthiness. Low-grade, but highly effective ferritic stainless can be accepted for use in various subframe section of the trams and the buses. Grade 1.4016 (AISI 430) was tested for particular fastening members used in frame of the buses. This steel grade used in mentioned structural parts was designed for the heterogeneous weld joints with austenitic stabilized steel 1.4541 (AISI 321). Welding wire OK Tigrod 16.95 ESAB (austenitic stainless steel 1.4370) was used as a filler material. Experimental butt welds were prepared as a homogeneous welding joints of grade 1.4016 using the same filler material. The analyses of the metallurgical changes in the heat-affected zone was necessary due to the frequent damage occurred along the welding line.

In initial experiments, both a tendency for intercrystalline corrosion in standard environments and a tendency to undergo pitting corrosion in $\mathrm{SO}_{2}$ environments were revealed for steel ASI 430. Degradation processes in the surface layer, interconnected with chemical passivation after welding, also were analysed (Schmidová et al., 2009). The results of existing studies emphasised the necessity for surface protection of the weld-affected zone. The selection of a suitable type of coating must be based on experimental verification of its anticorrosive efficiency on the heat-affected zone (HAZ).

The present work comprised a study of corrosion processes influenced by two effects: structural modifications attributable to the welding process and the stabilisation effects of several pigmented coatings. The effect of surface protection was confirmed experimentally by evaluating the differences in corrosion damage within the area affected by the heat of welding. The effect of the structure of individual sub-layers of the heat-affected zone was evaluated. The phase changes induced in the overheated zone, i.e., in the immediate vicinity of the fusion line, proved to be critical. Selected results of structural analyses are presented which document the established effects on the character and intensity of the corrosion process, and on the static strength of the weld joint after corrosion. 


\section{Methodology}

The protective effects of model paints containing anticorrosive pigments on welded stainless steel ASI 430 were investigated. The composition of the tested organic coatings applied to plates made of material 1.4016 (AISI 430) used two types of organic binders and four types of anticorrosive inorganic pigments.

\subsection{Characteristics of raw materials used in organic coatings}

The adhesive present in one series of model coatings was a modified, solvent-borne alkyd resin containing $10 \mathrm{vol} \%$ of calcium metaborate as the anticorrosive inorganic pigment. The other anticorrosive pigments tested in the alkyd coating comprised zinc orthophosphate at 10 vol.\% and strontium chromate (10 vol.\%). The adhesive present in the other series of model organic coatings was an epoxide resin, tested with $10 \%$ of calcium metaborate and $10 \%$ of strontium chromate. Metallic zinc at 65 vol. \% also was tested as the anticorrosive pigment in epoxide resin coatings. The morphology of pigment particles is shown in Figures 1-4. The paints were prepared as model paints without any other pigments and additives. The steel was tested with 14 types of protective coatings.

Take in Figure 1

Take in Figure 2

Take in Figure 3

Take in Figure 4

Properties of the epoxide resin (organic binder 1):

\section{Composition:}

Viscosity at $23^{\circ} \mathrm{C}$ :

Dry matter:

Epoxy index:

Density:

Solvent:

Manufacturer:

Hardener:

Composition:

Dry matter:

Solvent:

Curing ratio:
$75 \%$ solution of epoxide resin of medium molar mass in xylene, $(75 \%$ solution of middle-molecular epoxy resin in xylene)

10.5 Pa.s

$75 \%$

$2.15 \mathrm{~mol} / \mathrm{kg}$

$1.04 \mathrm{~g} / \mathrm{cm}^{3}$

Xylene : n-butanol $=4: 1$,

Spolchemie a.s. = Ústí nad Labem, Czech Republic

Solution of modified hardener based on an adduct polyamine/ medium-molar-mass epoxide

$50 \%$,

Xylene (a mixture of isomers)

Epoxy resin hardener $=100: 40$.

\section{Properties of the alkyd resin (organic binder 2):}

\section{Composition:}

$60 \%$ solution of air drying alkyd resin modified by $62 \%$ of soya bean oil in white spirit without aromatic compounds
Viscosity $\left(23^{\circ} \mathrm{C}\right)$
3.7 - 4.7 Pa.s
Acidity:
$7 \mathrm{mg} \mathrm{KOH} / \mathrm{g}$ maximum

\subsection{Preparation of model paints}

The paints were dispersed in grinder, type Dispermat CV (WMA Getzmann GmbH, Verfahrenstechnik, Germany), filled with glass beads, diameter $2 \mathrm{~mm}$, for 45 minutes at $20,000 \mathrm{rpm}$. Immediately before application of the paint onto the test panels, the pigmented 
paints were homogenised using polyamine hardener ChS Telalite 160 (100 parts: 40 parts of hardener). Cobalt octoate $(0.5 \%)$ was added as a siccative to the alkyd-resin paints. Three pigmented and one non-pigmented alkyd-based paints, and three model pigmented epoxidebased model paints were prepared. Table I summarises the model paints and gives the sample designations.

Take in Table I

\subsection{Preparation of coatings on steel panels (steel ASI 430)}

Paints were applied by means of an applicator blade onto welded test panels (of ASI 730), dimensions $100 \times 150 \mathrm{~mm}$, thickness $1.5 \mathrm{~mm}$. The total thickness of dried coatings was $100 \pm$ $10 \mu \mathrm{m}$. The samples then were kept for 21 days under standard conditions in an airconditioned room at $21^{\circ} \mathrm{C}$, relative air humidity $50 \%$. An oblique cut, $10 \mathrm{~cm}$ in length, was made to the coated samples by means of a tool that cut through the coating down to the metallic surface.

\subsection{Corrosion tests}

Determination of anticorrosion efficiency in $\mathrm{SO}_{2}$ in the presence of condensed humidity

The test was based on the provisions of ISO 6988 - a cyclic corrosion test in a condensation chamber in the presence of $\mathrm{SO}_{2}$. Corrosion is accelerated in a hermetically closed chamber by the effect of condensing humidity and gaseous $\mathrm{SO}_{2}\left(1 \mathrm{dm}^{3} \mathrm{SO}_{2}\right.$ acts for 8 hours in a chamber with volume of $100 \mathrm{dm}^{3}$ ). Samples were exposed to the environment in 24-hour cycles - 8 hours water condensation at $36^{\circ} \mathrm{C}$ in the presence of $\mathrm{SO}_{2}$ and 16 hours drying at $23^{\circ} \mathrm{C}$. The samples were examined after 7,000-hours of exposure. If a coating were considered efficient in this test, it must have protected against $\mathrm{SO}_{2}$ and acidic condensed humidity at elevated temperature. Coatings based on the alkyd resin containing calcium metaborate, strontium chromate and the coating without any pigment, and also epoxide coatings containing calcium metaborate, zinc metal, strontium chromate and the coating without any pigment ( 7 numbered samples) all were tested in the above environment.

\section{Determination of anticorrosion efficiency in $\mathrm{NaCl}$ in the presence of condensed humidity}

This was a cyclic corrosion test in a chamber containing salt fog. Corrosion is accelerated by the effect of condensed humidity and $\mathrm{NaCl}$ at elevated temperature $\left(35 \pm 1^{\circ} \mathrm{C}\right)$. A twelve-hour cycle was divided into three parts: 6 hours exposure to salt fog $(5 \% \mathrm{NaCl}$ solution $)$ at $35 \pm$ $1^{\circ} \mathrm{C}$; 2 hours drying at $23^{\circ} \mathrm{C}$; and 4 hours condensation of distilled water at $40^{\circ} \mathrm{C}$. Samples were examined after a 7,000-hour exposure. To be considered efficient, a coating must protect against the effect of the $\mathrm{NaCl}$, increased humidity and elevated temperature.

Coatings were based on the alkyd resin containing calcium metaborate, strontium chromate and the coating without any pigment, and also epoxide coatings containing calcium metaborate, zinc metal, strontium chromate and the coating without any pigment ( 7 numbered samples).

\section{Comparison experiments}

The reference sample (no. 13) also was tested - it was not subjected to the corrosion test and served as a reference -representing the initial state. Coatings that did not contain pigments also were examined.

\subsection{Methods used to assess the corrosion tests}

After exposure to the two corrosive tests, the coatings were evaluated by methods based on the provisions of Standards ASTM D 610 and ASTM D 1654 - 92. Fourteen samples of pigmented coatings were assessed on the basis of the results from the corrosion tests. 


\section{Overall assessment of anticorrosive efficiency}

The formula used to calculate the overall "degree of corrosion protection" was the same for all tests undertaken. Corrosion effects were assessed according to a ranking scale by assigning numbers of points from zero to 100 (Kalendová, 1998). The overall anticorrosive efficiency was calculated as the arithmetic mean from the following assessed changes: the degree of base corrosion, the average extent of corrosion at the cut (in \%), and the degree of corrosion at the weld (in \%).

To enable the effect of structural changes induced by elevated temperatures to be assessed, samples were provided with a weld joint. TIG welding was utilized in a protective atmosphere of pure argon, with excess material type 1.4370 , using an austenitic welding rod, type OK Tigrod 16.95 (ESAB).

In view of the objective of the experiment, assessment of the corrosion tests was supplemented with the analyses necessary to identify the mechanism of corrosion attack and the effect of the structural degradation of the material studied. The analyses thus comprised the following evaluation stages:

(1) Evaluation of overall efficiency of the coatings according to ASTM 1654-92 and ASTM D 610.

(2) Macroscopic evaluation of the depth of corrosion damage; non-etched metallographic scratch patterns were examined by means of an image analysis system.

(3) Analysis of structural modifications due to welding; metallographic examination specimens perpendicular to the weld joint.

(4) Identification of the corrosion mechanism; the state of the surface after the corrosion test was evaluated and metallographic analyses undertaken in transverse sections. The position of the assessed location within the HAZ was determined macroscopically; the effects on the corrosion mechanism of structural parameters such as the grain shape, proportion and distribution of secondary phases, etc., were evaluated microscopically.

The system of taking samples for individual analyses, including the position of the metallographic examination specimens evaluated, is evident from Figure 5; etching was carried out in Vilella-Bain reagent.

Take in Figure 5

\section{Results}

\subsection{Assessment of corrosion damage intensity}

The effectiveness of the coatings was evaluated according to ASTM D 1654-92 and ASTM D 610; Corrosion damage to the substrate, inside the cut, and in the HAZ, were taken into account separately - see Table II. Some selected contrasting results from the visual assessments of the corrosion damage are presented in Figures 6A through C.

\section{Také in Table II}

\section{Take in Figures 6 A-6C}

The results showed $100 \%$ anticorrosion efficiency in the two environments: full protection of both the base material and the weld joint by the epoxide coating with a high concentration of zinc metal.

The remaining coatings exhibited a limited passivation effect at mechanical damage in the cut area. In alkyd-based coatings containing calcium metaborate, zinc phosphate, or strontium chromate, the above effect was observed only in $\mathrm{SO}_{2}$ : in the $\mathrm{NaCl}$ environment the degree of 
material stabilisation was sufficient. The fact that all coatings provided fully functional protection against degradation caused by welding represented an important contribution to the solution of the problem at hand. Paradoxically, in the area beneath the alkyd coating containing zinc phosphate, slight damage to the base material not affected by welding was observed, while the anticorrosion function on the ferritic steel inside the HAZ area was preserved. It follows from the results of structural analysis presented below that protection can be attributed to a specific effect of structural modification inside the HAZ on the mechanism of corrosion.

Contrary to the aforementioned results, substantial corrosion attack was evident primarily in the area of the weld joint on samples with epoxide-based coatings containing zinc chromate and calcium metaborate. Corrosion tests of material protected by means of epoxide-based coatings containing calcium metaborate produced important results: maximum corrosion damage took place in the vicinity of the weld joint in $\mathrm{SO}_{2}$. By contrast, in $\mathrm{NaCl}$ the coating exhibited $100 \%$ protection in the $\mathrm{NaCl}$ solution. The two samples presenting the accompanying structural or phase effects for these coating types were analysed metallographically. Surface treatment by means of epoxide coating containing strontium chromate exhibited comprehensive anticorrosion protection of the original ferritic stainless steel in $\mathrm{NaCl}$. In that environment, the degradation effect both of mechanical damage to the coating and post-weld structural modifications were observed. In the $\mathrm{SO}_{2}$ environment, a loss of passivation ability by the ferritic steel was evident in regions outside the two tested areas; the fact that the intensity of corrosion damage exhibited approximately identical levels is of interest in this context. Again, the specific effect of phase changes inside HAZ on initiation of corrosion is subject to speculation.

\subsection{Structural change brought about by welding}

The original structure of the steel and the effect of the welding technology employed were evaluated for the reference sample that had not been subjected to the corrosion test. The structure of the quality ASI 430 material employed exhibited an homogeneous ferritic structure with distinctive carbide distribution in lines along the forming direction; the original structure is shown in Figure 7.

Close to the weld joint, where the welding temperature did not exceed $850-900^{\circ} \mathrm{C}$, the structure comprising ferrites and carbides was preserved. Inside the HAZ, where the welding temperature exceeded the above values, the material assumed a two-phase ferritic-austenitic structure in conformity with the phase diagram of the system Fe-C-Cr (Figure. 8). In view of the actual heating and cooling rates, austenite can be partially depleted of chromium, compared to the ferritic zone. Due to accelerated cooling inside the re-austenitization zone, austenite was transformed to martensite; the resulting structure of this zone then consisted of martensite, ferrite and carbides - Figure 9.

Another pronounced effect of welding comprised an intensive rate of growth in grain size after heating to temperatures where the material exhibited a fully ferritic structure (above $1350^{\circ} \mathrm{C}$ ). Although subsequent cooling partially had resulted in formation of austenite, whose fraction increased up to about $1100^{\circ} \mathrm{C}$, the content of the austenitic phase, comprising delta ferrite, in part decreases by reconversion to alpha ferrite. Thus, the mechanism did not result in a substantial grain refinement. The coarse-grain structure was not restrained by subsequent phase transformation processes during cooling, which is standard in low-alloy steel. This resulted in the observed intensive grain coarsening in a zone approximately $1 \mathrm{~mm}$ wide from the fusion line towards the base material.

The morphology of the two-phase region corresponded to the Widmanstättan structure of unalloyed or low-alloy carbon steel. The effect took place during rapid cooling of the twophase region where austenite was formed preferentially on grain boundaries or inwards with a certain crystallographic orientation, as a result of the preceding intensive grain coarsening. 
Intensive grain coarsening in the steel sublayer heated above some $1350^{\circ} \mathrm{C}$ was eliminated in part by the initial plastic strain of the steel. The accumulated internal energy induced recrystallisation mechanisms, resulting in grain refinement upon the subsequent new heating. This mechanism represents an important positive factor in welding. The temperatures used in standard hot-forming operations of these steels lie inside the two-phase zone. Interstitial carbon and nitrogen expand the austenitic zone towards higher temperatures or, at a constant temperature, support reduction of delta-ferrite in the two-phase region. Formation of precipitates based on carbon and nitrogen was revealed in the immediate vicinity of the fusion line, in the region of the most intensive grain coarsening - Figure 10. Very fine precipitates were involved, present mostly at the boundaries of subgrains or of more extensive primary precipitates. Subgrain formation is the result of relaxation mechanisms close to the fusion line, i.e., in a zone where the effects related to post-welding internal stress are the most intensive. In this instance, intracrystalline precipitation did not play a decisive role in degradation of corrosion resistance of the layer.

Take in Figure 7

Take in Figure 8

Take in Figure 9

Take in Figure 10

\subsection{Assessment of corrosion damage mechanism}

Visual, non-destructive evaluation established pitting corrosion was predominant in both the base material and the weld-affected layers - see, for example, the surface of the sample after removal of the epoxide coating containing strontium chromate in $\mathrm{SO}_{2}$ (Figure 11). Once the products of corrosion were removed, corrosion proceeding into the material depth was apparent at the bottom of the pit as a consequence of the grain structure and distribution of carbides. The depth of the corrosion attack was assessed metallographically in transverse cuts.

In the given sample, the extent of pitting corrosion inside HAZ (Figure 12, zone "A") and the base material not affected by welding (Figure 12, zone "B") was comparable. It was established also, for the entire experimental set, that the pitting mechanism of corrosion continued under the conditions where the corrosion process was accelerated after mechanical damage to the coating - Figure 13. The increased extent of corrosion damage was proportional to the cut depth. The rate of proceeding corrosion was affected in those surface treatments where - in the $\mathrm{SO}_{2}$ environment - anticorrosion efficiency of the protective coating was limited to spontaneous steel passivation (i.e., in pigments based on calcium metaborate, zinc phosphate and strontium chromate). In the environments consisting of a $5 \%$ mist of neutral $\mathrm{NaCl}$, the anticorrosion efficiency of all of the aforementioned coatings was preserved after surface damage.

Although the corrosion impact did not exhibit any visual differences in corrosion character, metallography established a dependence on the structure of the steel. Fundamental differences in the mechanism of corrosion damage were identified as a result of modifications to the metallurgical structure that had been introduced by welding.

Outside the HAZ, characteristic pitting corrosion of the ferritic steel took place (Figure 14, Figure 15). The more stable carbidic phase was preserved inside the corrosion pits. In none of the tested variants did a preferential progress of corrosion take place in connection with line precipitation of carbide. In other words, no reduction was observed in the concentration of active chromium in the immediate vicinity of carbides. In addition, inside those microregions of the material where decohesion of carbides took place during the sheet forming process, such microscopic discontinuities did not accelerate the corrosion process.

A different character of corrosion was revealed inside the heat-affected structure. As stated previously, the steel structure was completely transformed there into a two-phase, ferritic- 
martensitic structure as a result of phase modifications. The higher stability of martensitic steel compared to ferritic steel resulted in preferential development of corrosion of the ferritic phase. Thus, in areas that exhibited a two-phase structure, the character of corrosion changed to 'selective'. This mechanism prevailed in all sublayers of the two-phase HAZ. Morphological differences in the structure of the layers resulted in differences in the development of corrosive attack. The above difference was most obvious in the zone immediately abutting the fusion line and at the transition to material not affected by welding.

At the boundary of the weld metal, the martensitic phase abutted the zone with coarse grain structure; the preferential progress of corrosion outside the martensitic structure thus resulted in a certain insulation of grains damaged by corrosion. The appearance of layers affected by corrosion became typical of intercrystalline damage.

On the other hand, in zones with fine grain structure and linearly-distributed phases, preferential corrosion brought about a local effect of subsurface corrosion - Figure 16, Figure 17; and a reduced intensity of corrosion was observed visually inside this zone.

Take in Figure 11

Take in Figure 12

Take in Figure 13

Take in Figure 14

Take in Figure 15

Take in Figure 16

Take in Figure 17

\section{Discussion}

Amongst the adverse effects of the thermal and stress cycles that accompany welding, the typical and most often discussed property of the given type of corrosion resistant stainless steel is its susceptibility to grain coarsening at high temperatures and subsequent intercrystalline corrosion.

Weld damage very often is associated not only with a loss of passivation ability. It was observed during the present tests that the diffusion of carbon led to a phase change in the region containing carbon-enriched grain boundaries. This process, resulting in a transformation to martensite along the boundaries of coarsened ferritic grains, generally is considered to be a degradation of the structure.

During experimental assessment of adhesion and the protective effect of variant coatings it was observed that a specific process took place in the two-phase HAZ of steel AISI 430. The phase transformation resulted in a change in the mechanism of corrosion attack due to preferential corrosion of the ferrite. Pitting corrosion inside HAZ was suppressed, a zone characterised with selective corrosion attack was formed, and the progress of corrosion was strongly influenced by the structure's thermal history. In overheated steel, the tendency towards intercrystalline corrosion was suppressed and in the fine-grain zone after structural degradation, the degree of corrosion attack evident at the specimen surface was somewhat attenuated.

Metallurgical changes that took place during thermal loads above 0.7 of the melting temperature were connected to the often-limiting decrease in corrosion resistance (Demo, 1977). The content of interstitial elements, especially C, N and O, significantly influences the tendency towards high-temperature degradation. At such temperatures, these elements are present in the solid solution of a ferritic, potentially ferritic-austenitic, matrix. During cooling, precipitates are formed inter- or intra-granulary. Intercrystalline corrosion takes place in the first instance and a loss in plasticity is the consequence of the second.

Nitrogen exhibits the most pronounced adverse effect on material toughness. At a critical combined content, $\mathrm{C}+\mathrm{N}$ precipitation cannot be suppressed by rapid cooling. The formation 
of relatively stable titanium or niobium carbides may suppress degradation, as manifested both by improved corrosion resistance and a decreased susceptibility to embrittlement. The formation of aluminium nitrides and oxides also decelerates grain growth at such critical temperatures. The negative effect of grain growth is most pronounced in materials containing very low proportions of $\mathrm{C}+\mathrm{N}$ (Plumtree and Gullberg, 1980). Issues related to localisation of precipitates inside the microstructure have been discussed recently. One theory (Demo, 1977) is based on the degradation effect of intragranular precipitates that restrict the movement of dislocations. On the other hand, contributions published by Plumtree and Gullberg (Plumtreee and Gullberg, 1980) and Wright (Wright, 1980) link intragranular brittle damage with precipitation along grain boundaries, which reduces the energy necessary for nucleation of intercrystalline cleavage.

In experiments conducted during the present trials, precipitation of fine plate-like carbides was observed mostly within highly coarsened grains, where a carbide-free zone formed close to the boundaries.

Individual theories dealing with metallurgical character of degradation in the temperature range $425-550^{\circ} \mathrm{C}$ remain controversial. The dominant experimentally supported opinion is that degradation results from the formation of coherent precipitates (Marcincowski, 1964). At temperatures below $550^{\circ} \mathrm{C}$ a ferritic component partly enriched with chromium is formed, whose presence increases the tendency to a loss of steel plasticity. In the present context it should be noted that, for such embrittlement, or in connection with the underlying processes, a marked decrease in corrosion resistance may occur (Zappfe and Worden, 1951). Selective attack on the iron-enriched ferritic component is contributory as the source of this degradation. Anticorrosion properties can be recovered temporarily by short-term annealing at $550-600^{\circ} \mathrm{C}$. Excessive annealing time brings about a risk of a sigma-phase production, in particular in steels containing a higher proportion of chromium. According to a model proposed by Williams and Barbaro (Williams and Barbaro, 2005) boron and vanadium are elements that participate in the mechanism. The authors point out that dissolution of vanadium carbides occurs at temperatures close to $800^{\circ} \mathrm{C}$, followed by the formation of chromium carbides.

With regard to factors affecting corrosion resistance, the instances most often mentioned in connection with occurrence of the martensitic phase at grain boundaries include intercrystalline corrosion in $\mathrm{NaCl}$ environments (Lippold and Kotecki, 2005). The instances concerned included corrosion attack and subsequent destruction of the material at the phase boundary ferrite/martensite under the combined effect of applied and residual stress. The paper mentions concurrent effects of steel sensitisation due to the production of chromiumrich carbides and the reduced level of active chromium at the phase boundary. The combined effect thus results in the decline of passivation ability at grain boundaries after welding.

In the present work it was observed that a process prevailed whereby a precipitate-free zone was formed at the grain boundaries in response to ferrite-austenite-martensite phase transformation. Thus, at the grain boundariew themselves and, accordingly, across this entire zone, a certain increase in the consequent residual stress must be considered. In the zone where growth of ferritic grains was the most intensive, removal of interstitial elements during the austenitisation stage was not efficient throughout the entire grain volume and the formation of very fine plate-like precipitates was evident within the grains.

On the basis of the performed analyses it can be stated that in the investigated technology precipitates are formed both inter- and intra-granularly, depending on the cooling rate and the size of ferrite grains. The source is oversaturation of the ferrite with carbon or nitrogen at higher welding temperatures. the solubility of these two elements in steels containing $17 \%$ chromium decreased rapidly; for carbon, from $0.15 \mathrm{wt} . \%$ at $1400^{\circ} \mathrm{C}$ to about $0.03 \mathrm{wt} . \%$ at $1000^{\circ} \mathrm{C}$, and for nitrogen, from approximately $0,08 \mathrm{wt} . \%$ at $1300^{\circ} \mathrm{C}$ to less than $0.02 \mathrm{wt} \%$ at $900^{\circ} \mathrm{C}$. Precipitation of secondary phases thus is possible even with a content below 0.03 wt.\% carbon and below $0.05 \mathrm{wt} . \%$ nitrogen, in both instances in the absence of stabilising 
elements such as $\mathrm{Ti}, \mathrm{Nb}$ or $\mathrm{Al}$. The carbides $\mathrm{M}_{23} \mathrm{C}_{6}$ and $\mathrm{M}_{23}(\mathrm{CN})_{6}$ or chromium nitrides are typical for the tested steel AISI 430.

\section{Conclusions}

Structural change induced by welding comprised marked coarsening of the grains combined with transformation to a two-phase, ferritic-martensitic structure. The much higher solubility of interstitial elements in austenite during heating (for steels containing $17 \%$ chromium it was some $0.32 \mathrm{wt} . \% \mathrm{C}$ and $0.41 \mathrm{wt} . \% \mathrm{~N}$ at $1200^{\circ} \mathrm{C}$ ) gave rise to two effects on the anticorrosion properties of the tested steel:

- Suppressed precipitation along the boundaries of ferrite grains, resulting in a lower tendency for this non-stabilised steel to sustain intercrystalline corrosion.

- Short-range diffusion of carbon and nitrogen from ferrite to austenite. The local concentration of these constituents decreased and a zone was formed along the boundary of coarsened ferritic grains that was free from precipitates.

At higher cooling rates, i.e., close to the fusion zone, precipitation within the interior of grain clearly prevailed in the instances studied. A lower cooling rate and a structure consisting primarily of fine grains in the zone between HAZ and the base material facilitated carbide precipitation at the boundaries of ferritic grains.

The character and intensity of precipitation influenced the corrosion characteristics of the tested steel locally and also affected the anticorrosion efficiency of individual tested coatings.

The following summary conclusions can be stated:

i. Selective corrosion of the weld-affected zone was induced, rather than pitting corrosion of the base material.

iii.It was demonstrated that epoxide-based coatings containing a high proportion of zinc metal could provide reliable anticorrosive protection.

\section{Recommendations}

The results confirmed that it was possible to eliminate the effects of degradation processes in non-stabilised ferritic steel by reducing the heat input during welding. In a number of specific applications these possibilities are restricted and exhibit relatively low efficiency; i.e., elimination of sensitisation by other processes such as post-weld heat treatment, or controlled degrees of semiproduct deformation. This further highlights the practical importance of weld surface protection, e.g. on welded structures, where troublesome features may prevent adequate cleaning of pickling agent residues. The potential value of anticorrosion protection of structurally degraded steel layers has been verified using epoxide-based coatings containing a high concentration of zinc metal (65\%). The findings demonstrated that transformation to a two-phase structure does not adversely affect the corrosion resistance of weld joints. An increase in the notch sensitivity of the affected zones must be accommodated, i.e., this should be respected during the design of the welded structure. The consequences of martensite formation may be of decisive importance for the given type of stainless steel when other degradation processes taking place at the boundaries of coarsened ferritic grains are taken into account. The presence of hydrogen has the same effect here as in non-alloy steel containing a higher amount of carbon, i.e., encourages crack initiation at low temperatures. Enhanced protection during the welding process therefore is recommended, potentially also with additional heating to induce controlled hydrogen diffusion out of the weld metal and from the heat-affected zone after welding. 
Another approach may involve support given to austenite at high temperature; when the concentration of austenite-forming elements suffices for its stabilisation during cooling from the welding temperature, the resulting structure after the welding process is austenitic-ferritic.

\section{Acknowledgements}

This work has been supported by the Research Centrum of Railway Vehicles resolved under sponsorship of the Ministry of Education, Youth and Sports of Czech Republic, Project No. $1 \mathrm{M} 0519$.

\section{References}

Barbucci, A., Cerisola, G., Cabot, P. L., (2002), "Effect of cold-working in the passive behavior of 304 stainless steel in sulfate media“, Journal of the Electrochemical Society, Vol. 149, No. 12, pp. B534-B542.

Demo, J. J., (1977), "Structure and constitution of wrought ferritic stainless steels", Handbook of Stainless Steels, Peckner, D., and Bernstein, I. M., eds., McGraw-Hill, New York.

Kalendová, A., (1998), "Anticorrosive spinel-type pigments of the second generation" AntiCorrosion Methods and Materials, Vol. 45, No. 5, pp. 344-9.

Lippold, J. C., Kotecki, D. J., (2005), Welding metallurgy and weldability of stainless steels, John Wiley \& Sons, Inc. ISBN 0-471-47379-0.

Lo, K. H., Shek, C. H., Lai, J. K. L., (2009), "Recent developments in stainless steels", Materials Science and Engineering, Vol. 65, Issues 4-6, pp. 39-104.

Marcincowski, M. J., Fisher, R. M., and Szirmae, A., (1964), "Effect of $500^{\circ} \mathrm{C}$ ageing on the deformation behaviour of an iron-chromium alloy", Trans. AIME, Vol. 230, No. 4, pp. 676-689.

Mohyla, P., (2004), "Effect of tempering temperatures on mechanical properties of weld joints in low-alloyed creep-resistant steels", Acta Metallurgica Slovaca, Vol. 10, No. 4, pp. 193 200.

Peguet, L., Malki, B., Baroux, B., (2007), "Influence of cold working on the pitting corrosion resistance of stainless steels", Corrosion Science, Vol. 49, No. 4, pp. 1933-1948.

Phadnis, S. V., Satpati, A. K., Muthe, K. P., Vyas, J. C., Sundaresan, R. I., (2003), "Comparison of rolled and heat treated SS304 in chloride solution using electrochemical and XPS techniques" Corrosion Science, Vol. 45, No. 11, pp. 2467-2483.

Plumtree, A., Gullberg, R., (1980), "The influence of interstitial and some substitutional alloying elements", Toughness of Ferritic Stainless Steels, ASTM STP 706, R. A. Lula, ed., West Conshohocken, PA, 1980, pp. 34-55.

Rufnera, J., Gannona, P., Whitea, P., Deiberta, M., Teintzea, S., Smith, B, R., Chenba, H., (2008), "Oxidation behavior of stainless steel 430 and 441 at $800^{\circ} \mathrm{C}$ in single (air/air) and dual atmosphere (air/hydrogen) exposures", International Journal of Hydrogen Energy, Vol. 33, pp. 1392-1398.

Salvago, G., Fumagalli, G., Sinigaglia, D., (1983), "The corrosion behavior of AISI-304L stainless steel in $0,1-\mathrm{M}-\mathrm{HCl}$ at room temperature: 2. The effect of cold working", Corrosion Science, Vol. 23, No. 5, pp. 515-523.

Schmidová, E., Švanda P., Veselý, D., Kalendová, A., (2009), "Mechanism of degradation of stabilized corrosion-resistant steel during the welding cycle", Anti-Corrosion Methods and Materials, Vol. 56, No. 4, pp. 206-217. 
Vignal, V., Mary, N., Valot, C., Oltra, R., Coudreuse, L., (2004), "Influence of elastic deformation on initiation of pits on duplex stainless steels", Electrochemical and Solid State Letters, Vol. 7, No. 4, pp. C39-C42.

Warmelo, M., Nolan, D., Norrish, J., (2007), "Mitigation of sensitisation effects in unstabilised $12 \% \mathrm{Cr}$ ferritic stainless steel welds", Materials Science and Engineering, Vol. A, 464, pp. 157-169.

Williams, J. G., Barbaro, F. J., (2005), "Susceptibility and Prevention of Weld HAZ Sensitization and Intergranular Stress Corrosion Cracking in Various 12\% Cr Steels", Proceedings of AISTech, Charlotte, North Carolina, USA.

Wright, R. N., (1980), “Toughness of Ferritic Stainless Steels”, Toughness of Ferritic Stainless Steels, ASTM STP 706, R. A. Lula, (ed)., West Conshohocken, PA, pp. 2-33.

Zahumensky, P., Tuleja, S., Orszagova, J., Janovec, J., Siladiova, V., (1999), "Corrosion resistance of $18 \mathrm{Cr}-12 \mathrm{Ni}-2,5 \mathrm{Mo}$ steel annealed at 500-1050 degrees C“, Corrosion Science, Vol. 41, No. 7, pp. 1305-1322.

Zappfe, C. A., Worden, C. O., (1951), “A notch-bend test”, Welding Journal, Vol. 30, No. 1, pp. 47-54.

Figure 1 - Calcium metaborate (pigment 1), morphology and pigment properties

\section{Morphology (SEM, magnification 3000 x)}

Composition: $\quad \mathrm{Ca}\left(\mathrm{BO}_{2}\right)_{2}$

Density: $\quad 2.8$ g.cm $\quad \mathrm{cm}^{-3}$

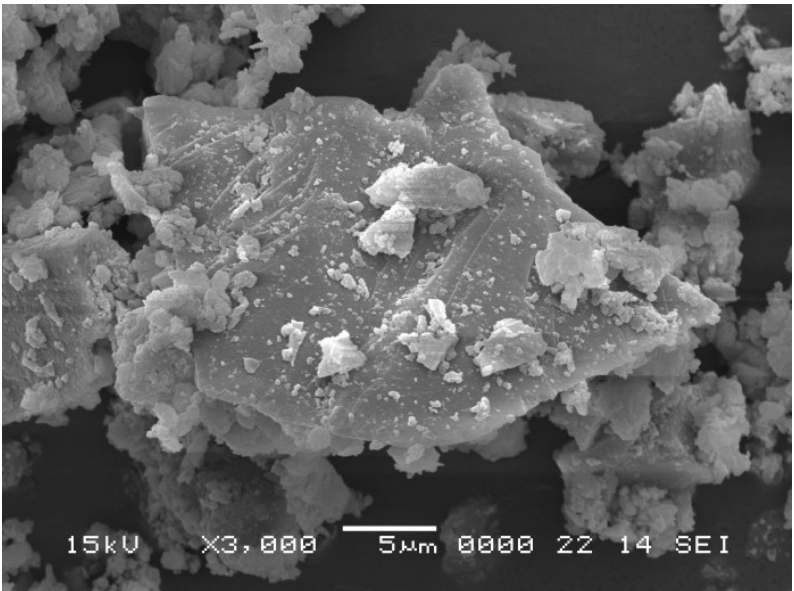


Figure 2 - Zinc phosphate (pigment 2), morphology and pigment properties

Morphology (SEM, magnification 3000 x)

Composition: $\quad \mathrm{Zn}_{3}\left(\mathrm{PO}_{4}\right)_{2} \mathrm{xH}_{2} \mathrm{O}$

Density: $\quad 3.3$ g.cm $\quad \mathrm{cm}^{-3}$

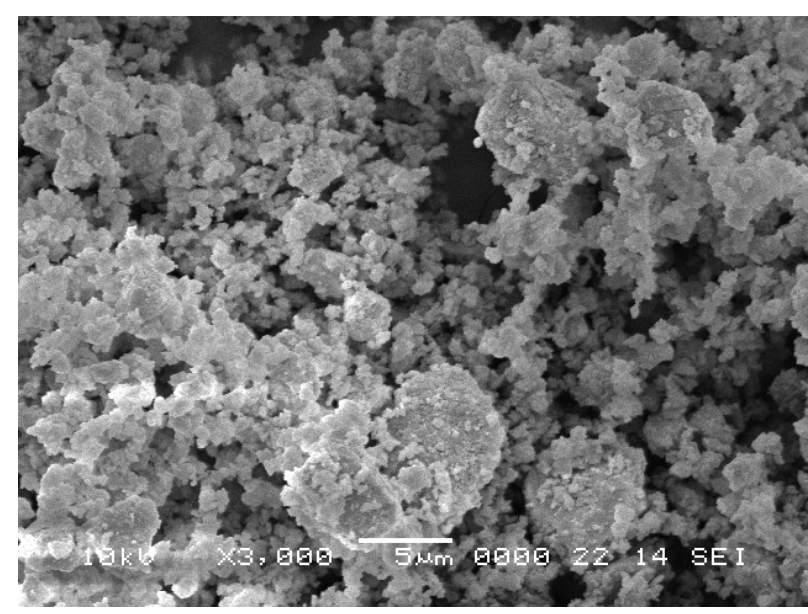


Figure 3 - Strontium chromate (pigment 3), morphology and pigment properties Morphology (SEM, magnification 3700 x)

Composition: $\quad \mathrm{SrCrO}_{4}$

Density: $\quad 3,84$ g.cm $\quad 3$

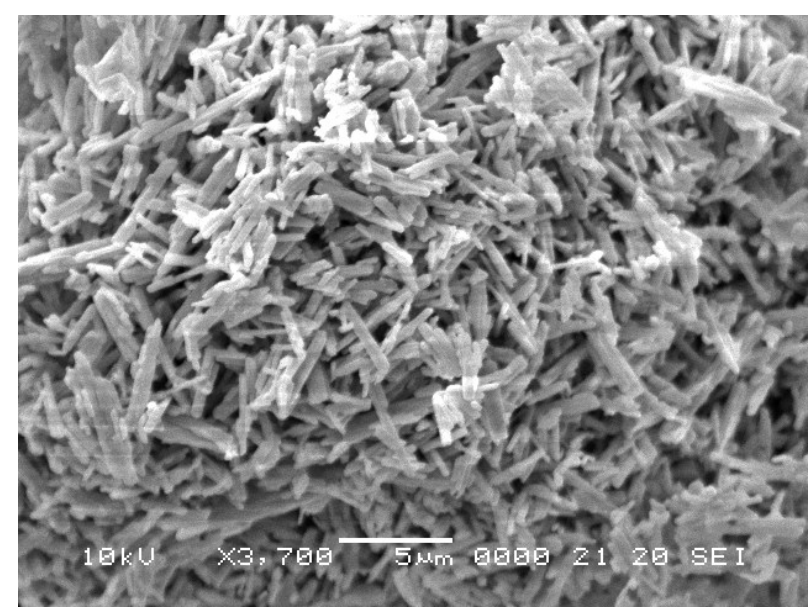


Figure 4 - Zinc metal (pigment 4), morphology and pigment properties

Morphology (SEM, magnification 5000 x)

\begin{tabular}{|c|c|}
\hline Composition: & Zinc metal (Zn) \\
\hline \multirow[t]{2}{*}{ Density: } & 6.99 g.cm ${ }^{-3}$ \\
\hline & $6.86 \mathrm{~g} / 100 \mathrm{~g}$ pigment \\
\hline CPVC: & 65 obj. $\%$ \\
\hline
\end{tabular}

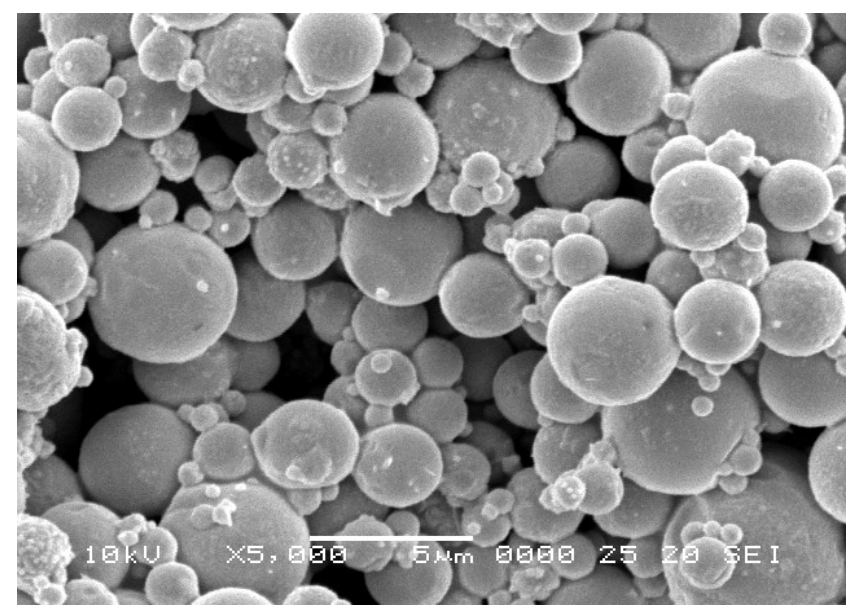


Figure 5 - Sampling scheme

A - for evaluation of the effect of mechanical damage of the coating upon corrosion

$\mathrm{B}$ - for analysing the effect of structural modifications after welding

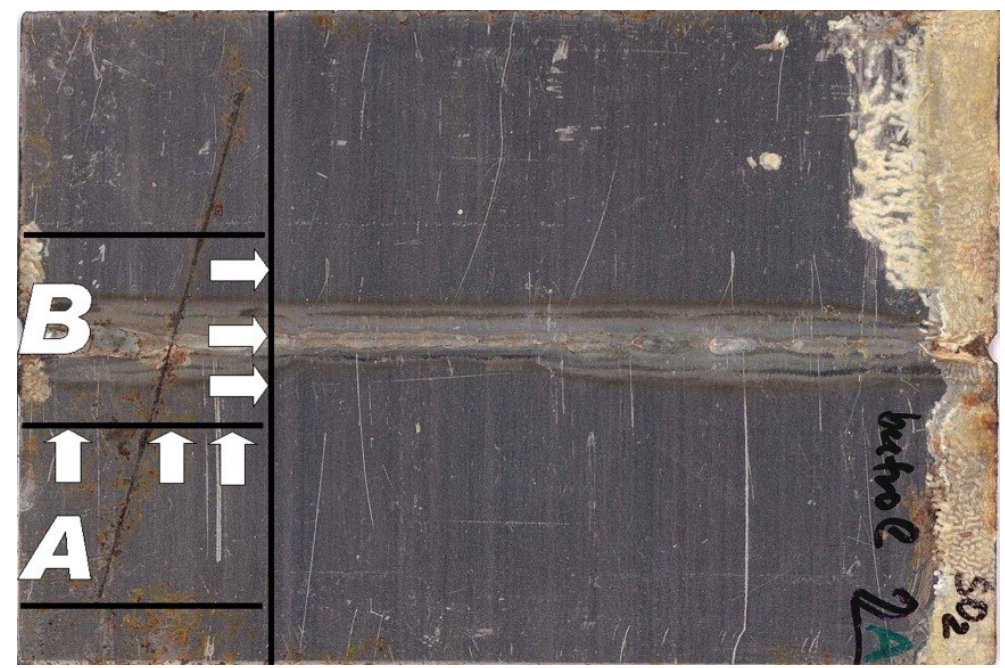


Figure 6 - Visually different corrosion damage

"A" Effect of mechanical damage at otherwise full anticorrosion efficiency: protection by an alkyd coating containing $10 \%$ of calcium metaborate in $\mathrm{SO}_{2}$

"B" Preferential corrosion damage of the weld joint: protection by means of epoxide coating containing $10 \%$ of strontium chromate in $\mathrm{NaCl}$

"C" Full anticorrosion efficiency: protection by means of epoxide coating containing
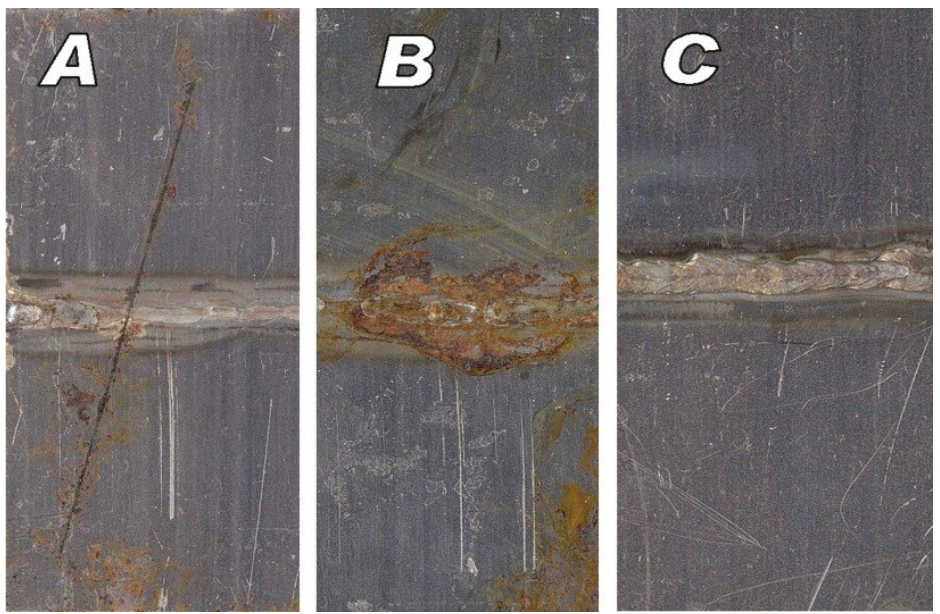
Figure 7 - Structure of unaffected zone of steel 1.4016 (magnification $5000 \mathrm{x}$ )

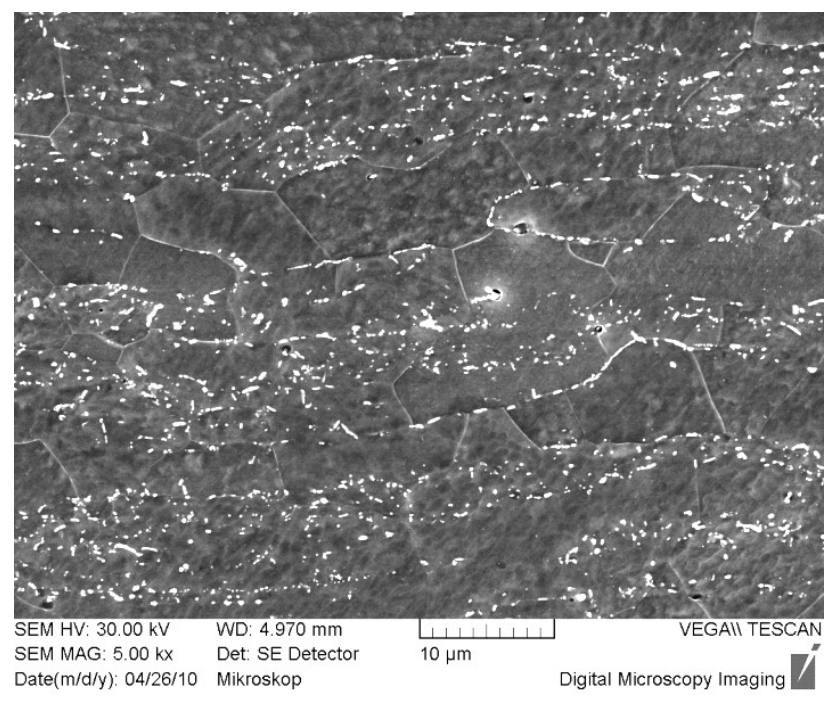


Figure 8 - Vertical section of the equilibrium diagram $\mathrm{Fe}-\mathrm{C}-\mathrm{Cr}$ at $17 \% \mathrm{Cr}$ [7]

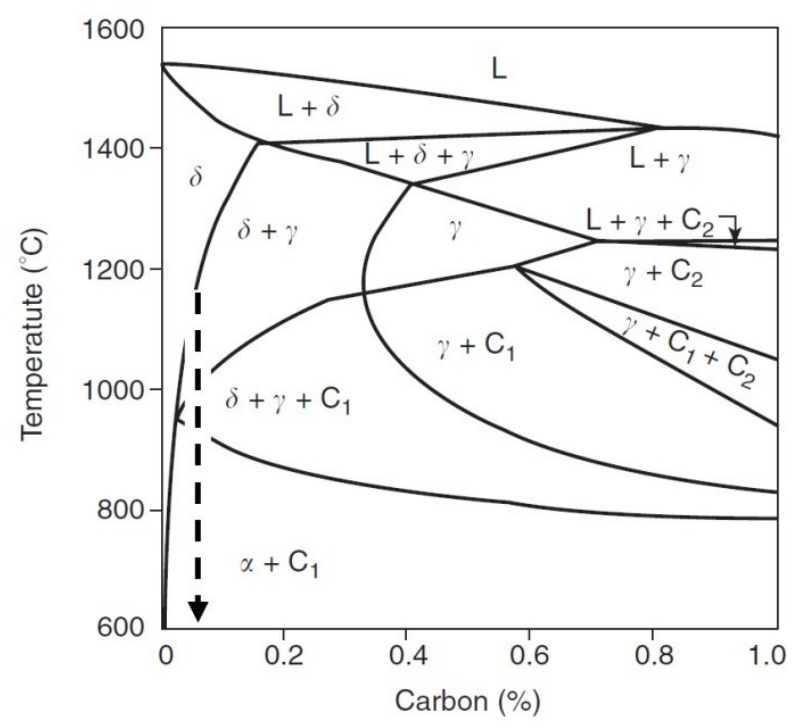


Figure 9 - Formation of martensite at the grain boundary inside HAZ (magnification $1000 \mathrm{x}$, area "B" in Figure 4)

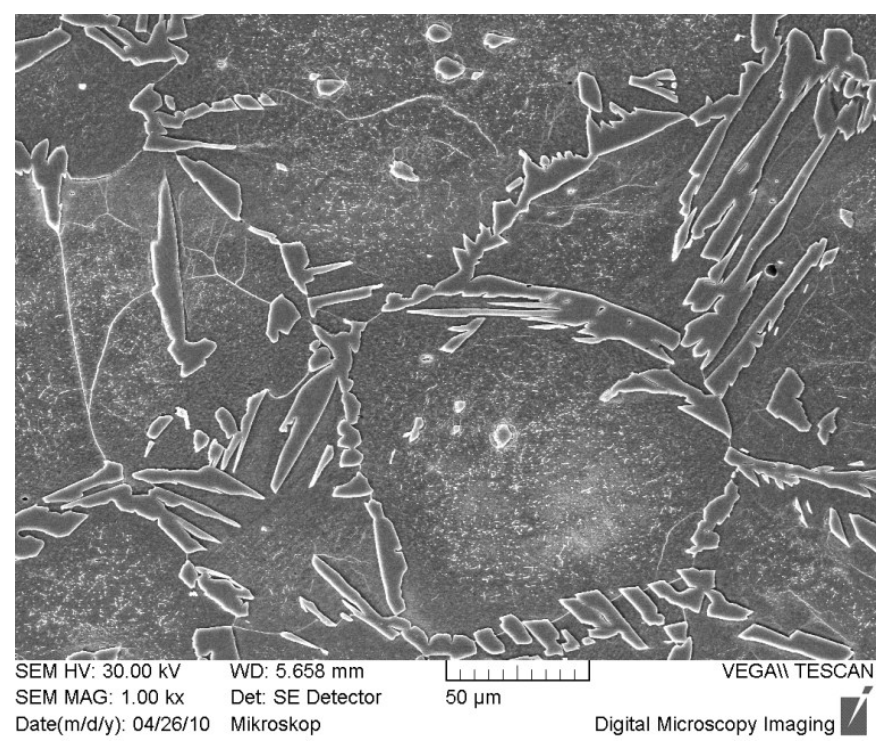


Figure 10 - Distribution of fine-grained carbides inside a coarse ferritic grain (magnification 5000x)

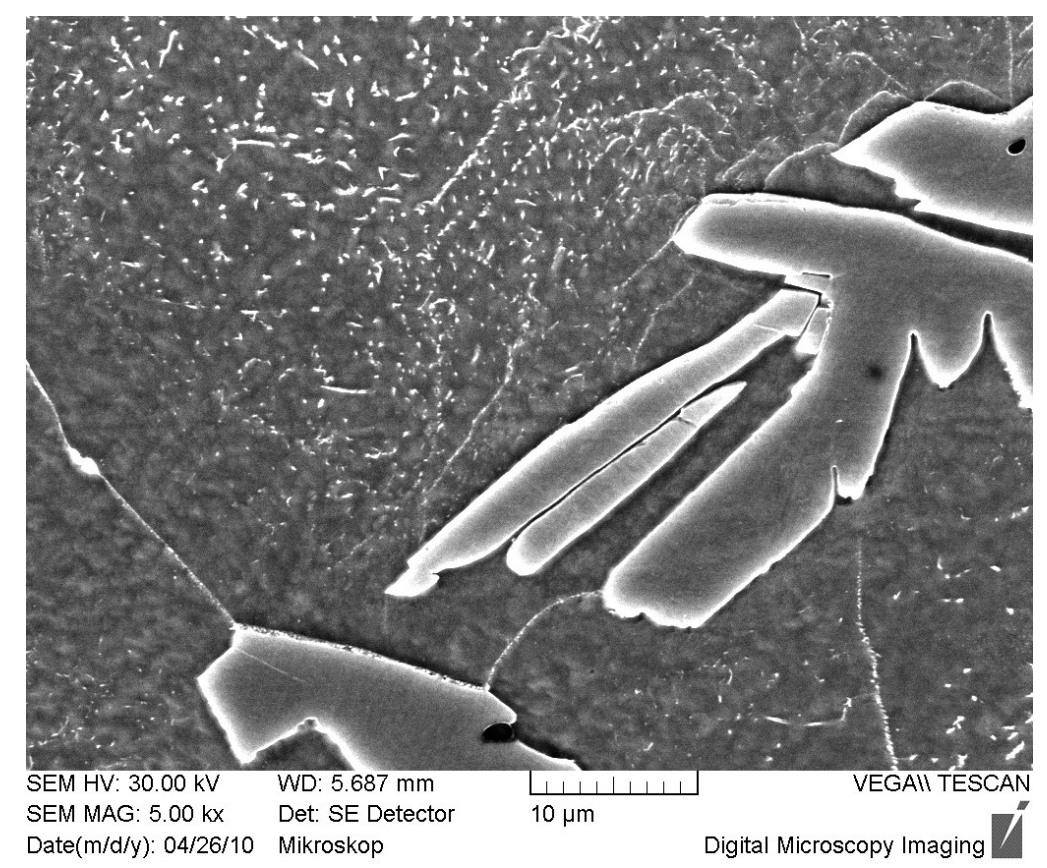


Figure 11 - Pitting corrosion outside HAZ

"A" magnification $250 \mathrm{x}$

"B" (magnification $2000 \mathrm{x}$ ) Interior of the corrosion pit after removal of corrosion

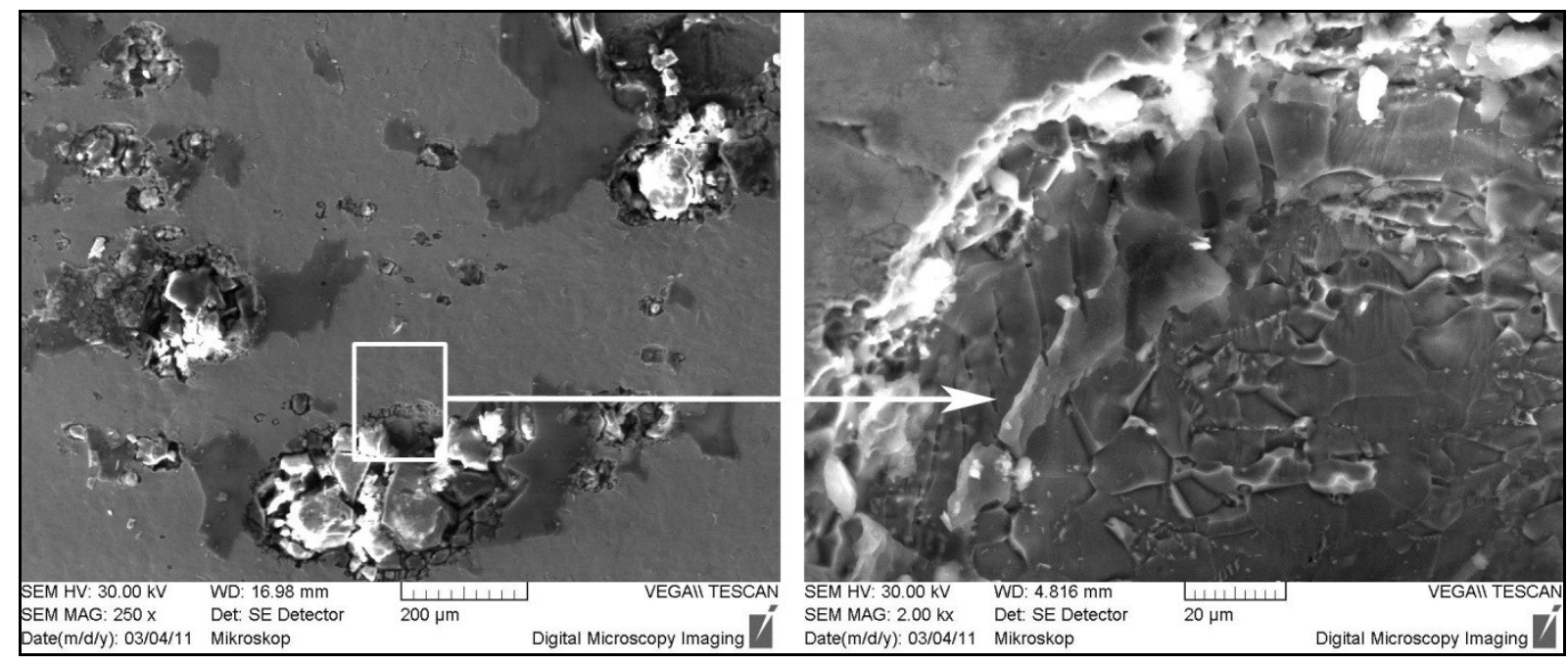

A 
Figure 12 - Pitting corrosion against the background of welding joint macrostructure. (magnification 25 x)

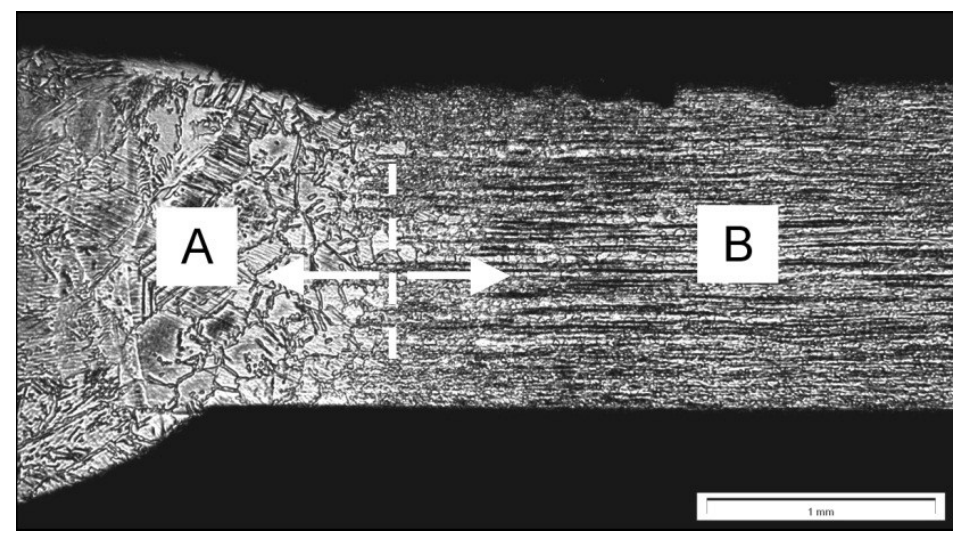


Figure 13 - Initiation of pitting corrosion at the place of mechanical damage (magnification $500 x)$

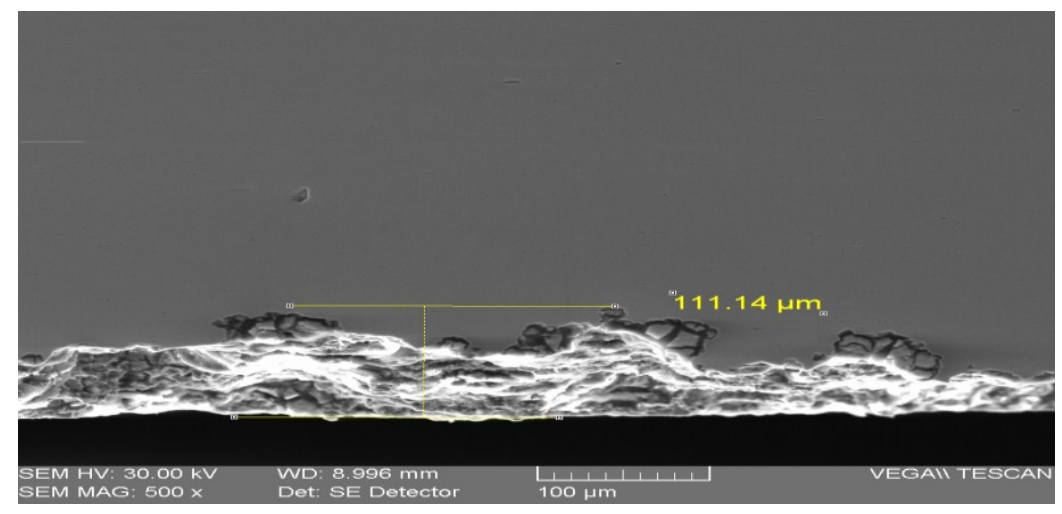


Figure 14 - Progress of corrosion inside the ferritic-martensitic steel structure (magnification $2000 \mathrm{x})$

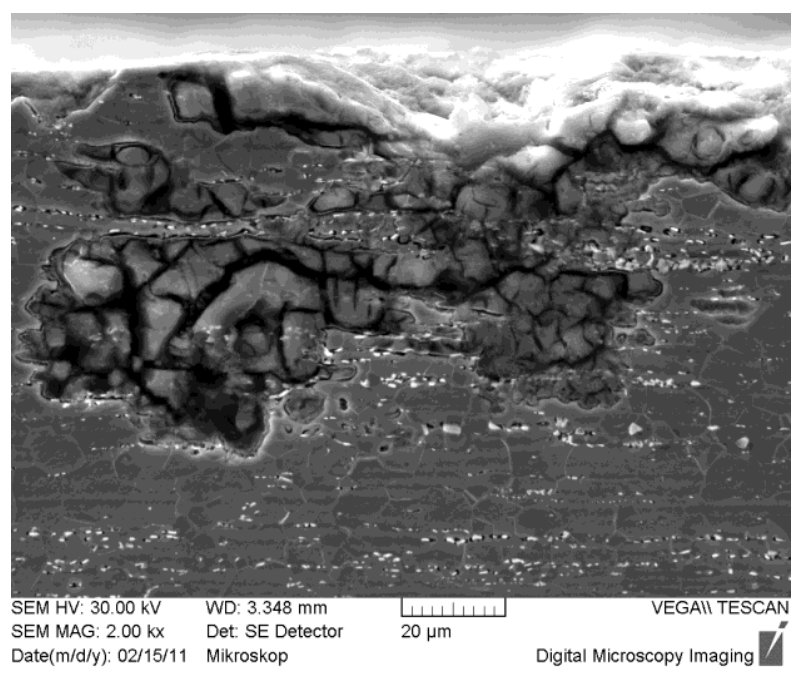


Figure 15 - Pitting corrosion of ferrite(magnification 4000x)

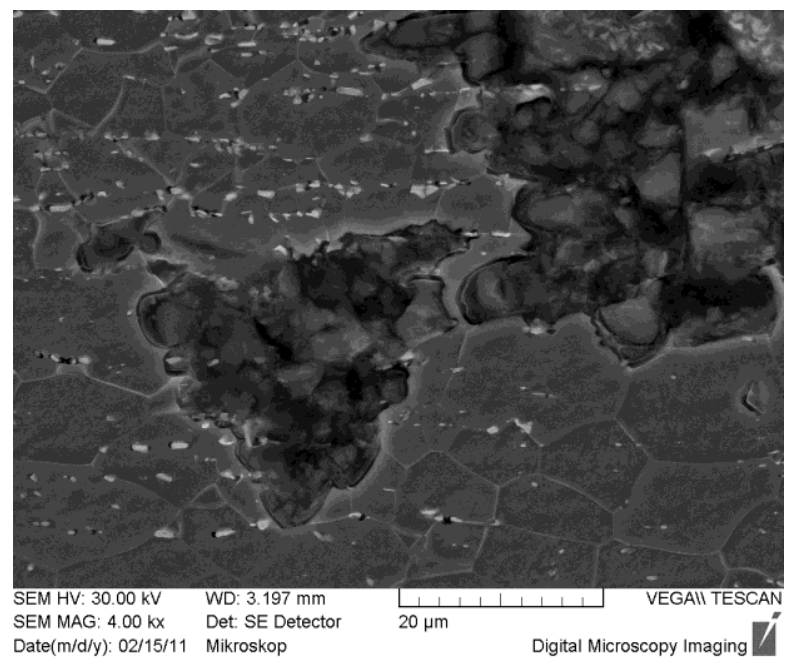


Figure 16 - Small polyedric formation of martensite in the fine-grained zone (magnification 7000x)

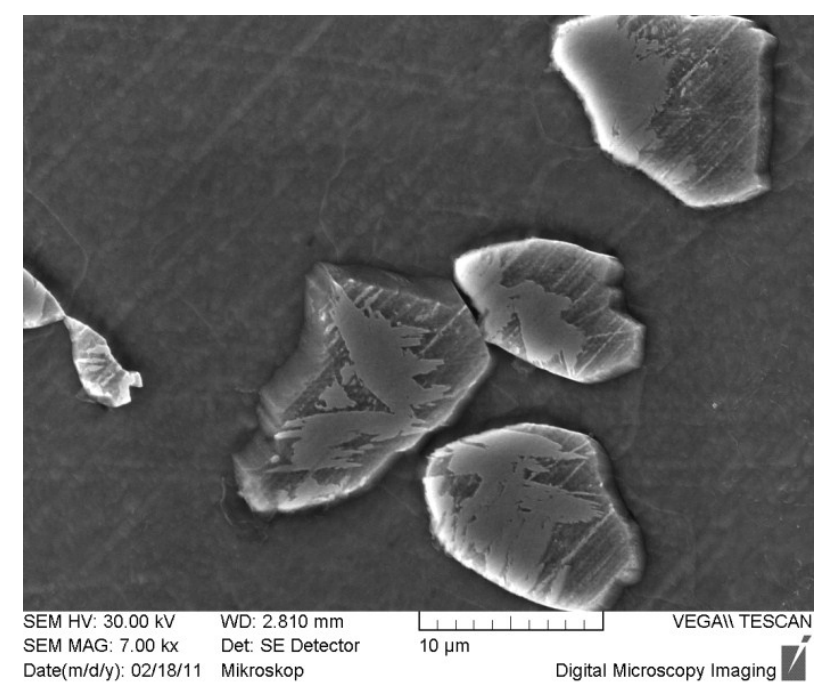


Figure 17 - Subsurface development of corrosion in the two-phase zone (magnification 1000x)

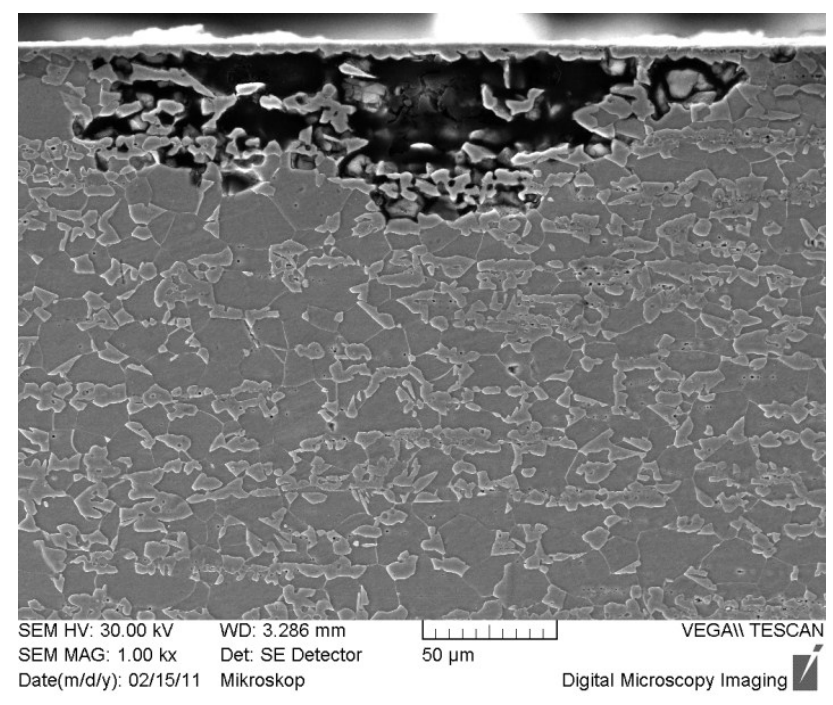


Table I - Review of protective coatings and their designation; corrosive media

\begin{tabular}{|c|c|c|c|}
\hline \multicolumn{2}{|c|}{ Model paints containing a combination adhesive/pigment } & \multirow{2}{*}{\multicolumn{2}{|c|}{$\begin{array}{l}\text { Corrosion } \\
\text { medium }\end{array}$}} \\
\hline Adhesive & Pigment & & \\
\hline $\begin{array}{l}\text { Modified alkyd resin } \\
\text { (Binder 1) }\end{array}$ & $\begin{array}{l}\text { Calcium metaborate } \\
\text { (pigment 1) }\end{array}$ & $\mathrm{NaCl}$ & - \\
\hline $\begin{array}{l}\text { Modified alkyd resin } \\
\text { (Binder 1) }\end{array}$ & $\begin{array}{l}\text { Calcium metaborate } \\
\text { (pigment 1) }\end{array}$ & & $\mathrm{SO}_{2}$ \\
\hline $\begin{array}{l}\text { Modified alkyd resin } \\
\text { (Binder 1) }\end{array}$ & $\begin{array}{l}\text { Zinc phosphate } \\
\text { (pigment 2) }\end{array}$ & $\mathrm{NaCl}$ & - \\
\hline $\begin{array}{l}\text { Modified alkyd resin } \\
\text { (Binder 1) }\end{array}$ & $\begin{array}{l}\text { Zinc phosphate } \\
\text { (pigment 2) }\end{array}$ & & $\mathrm{SO}_{2}$ \\
\hline $\begin{array}{l}\text { Modified alkyd resin } \\
\text { (Binder 1) }\end{array}$ & $\begin{array}{l}\text { Strontium chromate } \\
\text { (Pigment 3) }\end{array}$ & $\mathrm{NaCl}$ & - \\
\hline $\begin{array}{l}\text { Modified alkyd resin } \\
\text { (Binder 1) }\end{array}$ & $\begin{array}{l}\text { Strontium chromate } \\
\text { (Pigment 3) }\end{array}$ & - & $\mathrm{SO}_{2}$ \\
\hline $\begin{array}{l}\text { Modified alkyd resin } \\
\text { (Binder 1) }\end{array}$ & - & $\mathrm{NaCl}$ & - \\
\hline $\begin{array}{l}\text { Modified alkyd resin } \\
\text { (Binder } 1 \text { ) }\end{array}$ & - & - & $\mathrm{SO}_{2}$ \\
\hline $\begin{array}{l}\text { Epoxide resin } \\
\text { (Binder } 2)\end{array}$ & Zinc metal (pigment 4) & $\mathrm{NaCl}$ & - \\
\hline $\begin{array}{l}\text { Epoxide resin } \\
\text { (Binder } 2)\end{array}$ & Zinc metal (pigment 4) & - & $\mathrm{SO}_{2}$ \\
\hline $\begin{array}{l}\text { Epoxide resin } \\
\text { (Binder } 2)\end{array}$ & $\begin{array}{l}\text { Calcium metaborate } \\
\text { (pigment 1) }\end{array}$ & $\mathrm{NaCl}$ & - \\
\hline $\begin{array}{l}\text { Epoxide resin } \\
\text { (Binder 2) }\end{array}$ & $\begin{array}{l}\text { Calcium metaborate } \\
\text { (pigment } 1 \text { ) }\end{array}$ & - & $\mathrm{SO}_{2}$ \\
\hline \multicolumn{4}{|c|}{ Reference sample } \\
\hline $\begin{array}{l}\text { Epoxide resin } \\
\text { (Binder } 2)\end{array}$ & Strontium chromate (pigment 3 ) & - & $\mathrm{SO}_{2}$ \\
\hline $\begin{array}{l}\text { Epoxide resin } \\
\text { (Binder 2) }\end{array}$ & Strontium chromate (pigment 3) & $\mathrm{NaCl}$ & - \\
\hline
\end{tabular}


Table II - Evaluation of corrosion tests according to ASTM D 1654-92 and ASTM D 610

\begin{tabular}{ccccccc}
\hline Sample & \multicolumn{2}{c}{$\begin{array}{c}\text { Corrosion of base } \\
\text { metal }\end{array}$} & \multicolumn{2}{c}{ Corrosion in the cut } & \multicolumn{2}{c}{$\begin{array}{c}\text { Corrosion in the weld } \\
\text { joint }\end{array}$} \\
\cline { 2 - 8 } No. & $\begin{array}{c}\text { ASTM D } \\
\mathbf{6 1 0}\end{array}$ & $\begin{array}{c}\text { Evaluation } \\
\text { number }\end{array}$ & $\begin{array}{c}\text { ASTM D } \\
\mathbf{1 6 5 4 . 9 2} \\
{[\%]}\end{array}$ & $\begin{array}{c}\text { Evaluation } \\
\text { number }\end{array}$ & $\begin{array}{c}\text { ASTM D } \\
\mathbf{1 6 5 4 . 9 2} \\
{[\%]}\end{array}$ & $\begin{array}{c}\text { Evaluation } \\
\text { number }\end{array}$ \\
\hline 1 & 0 & 100 & 0 & 100 & 0 & 100 \\
\hline 2 & 0 & 100 & $0-0,5$ & 90 & 0 & 100 \\
\hline 3 & 0 & 100 & 0 & 100 & 0 & 100 \\
\hline 4 & 0,1 & 95 & $0-0,5$ & 90 & 0 & 100 \\
\hline 5 & 0 & 100 & 0 & 100 & 0 & 100 \\
\hline 6 & 0 & 100 & $0-0,5$ & 90 & 0 & 100 \\
\hline 9 & 0 & 100 & 0 & 100 & 0 & 100 \\
\hline 10 & 0 & 100 & 0 & 100 & 0 & 100 \\
\hline 11 & 0 & 100 & 0 & 100 & 0 & 100 \\
\hline 12 & 0 & 100 & $0-0,5$ & 90 & $>16$ & 0 \\
\hline 14 & 1 & 80 & $0-0,5$ & 90 & $0,5-1$ & 80 \\
\hline 15 & 0 & 100 & $0-0,5$ & 90 & $0-0,5$ & 90 \\
\hline
\end{tabular}

